\title{
Erratum to: Primary anterior cruciate ligament reconstruction in athletes: a 5-year follow up comparing patellar tendon versus hamstring tendon autograft
}

\author{
Johannes Leitgeb · Julia Köttstorfer · Rupert Schuster · Florian M. Kovar · Patrick Platzer • \\ Silke Aldrian
}

Published online: 28 June 2014

(C) Springer-Verlag Wien 2014

Erratum to: DOI 10.1007/s00508-014-0550-4

In the published article, the name of the co-author Julia Köttstorfer is not given correct. The correct name is: Julia Köttstorfer 